\title{
Childhood Extraskeletal Osteosarcoma
}

National Cancer Institute

\section{Source}

National Cancer Institute. Childhood Extraskeletal Osteosarcoma. NCI Thesaurus. Code C27376.

An osteosarcoma arising from the soft tissue, and occurring during childhood. 